\title{
Качественный посадочный материал, новые технологии и технику - картофелеводам России
}

\section{Н.Н. Колчин, В.И. Леунов}

Освещен мировой опыт с.- х. машиностроения и выделены основные причины отставания этой отрасли в РФ. Приведен ряд предложений по развитию и проведению комплексных работ по созданию и внедрению перспективных технологий и техники в сельское хозяйство России. Сформулированы основные задачи по созданию и производству с. - х. техники в современных условиях.

Ключевые слова: картофелеводство, техника, технологии.

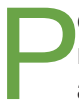
оссия обладает уникальным многозональным аграрным потенциалом и остается одним из крупнейших производителей разнообразной с.- х. продукции и сырья в мире. При двух процентах населения земного шара она располагает 9\% мировой пашни, 55\% процентами черноземных почв, 20\% запасов пресной воды.

Ключевые факторы повышения эффективного производства продукции сельского хозяйства - качественный семенной материал, современные машинные технологии, эффективная и надежная с. - х. техника, соответствующие кадры на местах, а также бережное обращение с природными ресурсами страны и с окружающей средой [1]. Общая схема базовой машинной технологий производства картофеля и овощей представлена на рисунке.

В прошлом столетии на основе новой отрасли науки - земледельческой механики, обоснованной академиком В.П. Горячкиным, была создана, активно работала и развивалась отечественная отрасль с.- х. машиностроения, как система создания и серийного производства техники для села. В послевоенные годы она была восстановлена и получила дальнейшее развитие. Активно создавались и серийно выпускались машины для комплексной механизации работ на многих культурах, в том числе на картофеле и основных овощах [2].

В результате этих работ, многие процессы производства в сельском хозяйстве нашей страны к концу прошлого века стали высокомеханизированными на основе отечественной техники (обработка почвы, посев и посад- ка - до 100\%, уборка разных с.- х. культур - 50-90\% и т.п.). Ряд отечественных сельхозмашин поставлялся на экспорт. Создатели и производители ряда моделей отечественной с.- х. техники были отмечены Государственными премиями страны [3].

Проведенные в нашей стране в начале 1990-х годов преобразования нанесли серьезный урон материально-технической базе отечественного АПК. Существующий парк техники изношен до $70 \%$, а доля устаревшей превышает 90\%. При этом нагрузка на технику возросла в разы по сравнению с нормативной. Так, на один трактор при нормативе 73 га она составляет 244 га, а на один зерноуборочный комбайн - до 354 га при норме 244 га [4]. На сегодня эти показатели практически не улучшились. В настоящее время в России заброшено около 40 млн га сельхозземель, на что указывал в своем Послании Федеральному собранию в 2016 году Президент РФ В.В. Путин и отмечал острую необходимость их восстановления [5].

По данным ООН, в нашей цепочке от поля до потребителя (производители, переработчики, продавцы и др.) теряется до 15\% продовольствия. При общем объеме его производства в 2017 году это принесло общие убытки более 5 трлн р.

Сельское хозяйство развитых зарубежных стран характеризуется сравнительно высоким уровнем применяемых технологий, насыщенностью техникой и ее общей новизной. В Германии количество тракторов на 1000 га составляет 64 шт., в Канаде 16 шт., в Аргентине - 8 шт. Схожая ситуация и по комбайнам. В ведущих странах Евросоюза и США основную массу картофеля и овощей производят в рамках машинных технологий, в том числе по технологиям точного земледелия с переходом на цифровые, с урожайностью 35-42 т/га и выше. Хранят убранную продукцию в местах выращивания в современных хранилищах. Так, в Великобритании на 1 га посадок картофеля приходится порядка 30 т емкостей для его длительного хранения. Широко практикуется и переработка сельхозпродукции.

Сегодня Минсельхоз России, вносивший до перестройки серьезный вклад в развитие отечественного производства сельхозпродукции, в том числе по картофелеводству, включая его семеноводство, и бывший основным заказчиком и потребителем отечественной сельхозтехники, практически устранился от этой важной и нужной работы. Министерство перестало быть заказчиком промышленных технологий и технических средств производства сельхозпродукции и не отвечает за обеспечение необходимого их уровня и количества на полях страны, вытекающего из Доктрины продовольственной безопасности России (Указ Президента РФ № 120 от 30 января 2010 года). При этом многие отечественные разработки достаточно широко используются за рубежом, а у нас остаются без должного внимания, что показывает определенное несовершенство отечественной патентной системы. В Доктрине четко обозначено, как одно из приоритетных направлений экономической политики государства, поэтапное снижение зависимости отечественного АПК от импорта технологий, машин, оборудования, семенного материала и других внешних ресурсов.

Резкое падение производства c. - х. техники в стране было отмечено в письме специалистов отрасли в адрес В.В. Путина, опубликован-

№11/2019 Картофель и овощи 
ном в газете «Известия» от 1 июня 2010 года.

Отсутствует стратегическое видение развития отечественного сельхозмашиностроения как технической базы развития АПК страны, способной эффективно создавать, производить и продвигать с. - х. технику на внутреннем и внешнем рынках, привлекать необходимые для этого ресурсы и управлять ими. Об этом свидетельствует Стратегия развития с. -х. машиностроения России на период до 2030 года, утвержденная 7 июля 2017 года премьером страны Д.А. Медведевым, которая предусматривает решение лишь отдельных задач. К тому же предыдущая аналогичная Стратегия на период до 2020 года по ряду позиций осталась невыполненной.

Вместе с тем, были ликвидированы Головные научно-исследовательские институты отрасли с.- х. машиностроения - НАТИ, ВИСХОМ и НИИ ТРАКТОРОСЕЛЬХОЗМАШ, МНОГИЕ специализированные ГСКБ, СКБ и заводы. Так, ликвидированы ГСКБ и два завода в г. Рязани - традиционном комплексном центре по созданию и производству техники для картофелеводства и овощеводства [6].

Основная проблема большинства предприятий отечественного сельхозмашиностроения состоя- ла в их технологической отсталости. Необходима была глубокая модернизация имеющихся и строительство новых заводов. К изготовлению отечественной с.- х. техники следует подключать предприятия страны с высокотехнологичным производством, а также изготовителей комплектующих изделий и новых материалов. Следует отметить, что сельхозмашины имеют достаточно много общих машинных элементов: рамы, ходовые системы, приводы и передачи, транспортеры и др. Такая их особенность широко используется за рубежом, поскольку облегчает их разработку и организацию производства.

Номенклатура техники велика и чрезвычайно разнообразна, особенно для нашего многозонального сельского хозяйства. В ней широко используются различные сложные механические, гидравлические, электрические, электронные, комплексные и прочие системы для оптимального выполнения технологических операций, передачи энергии, управления и обеспечения условий труда операторов, что требует для их создания и организации производства специалистов с высокой инженерной подготовкой. Их необходимо готовить в ведущих технических вузах страны.
Основные задачи, поставленные в свое время перед ВИСХОМ при его создании, по обоснованию и разработке новой сельхозтехники, в современных условиях остаются практически прежними. Одна из них - организация и проведение совместно с Минсельхозом РФ (с привлечением предприятий смежных ведомств) текущих и перспективных НИОКР на основе комплексных планов по созданию новой техники и ее производству по современным перспективным технологиям.

Отрасль с.- х. машиностроения должна иметь в качестве ведущего научного и организационного ядра современный федеральный Научнотехнический центр по сельхозмашинам, аналогичный головному институту ЦАГИ по авиации.

Картофель - одна из основных мировых с.- х. культур. Он возделывается в более, чем 100 странах мира. Его производство в мире в 2013 году составляло 376,5 млн т, что на 109,7 млн т, или на 41,1\% больше, чем в 1990 г. (табл.). В том году в мире под картофелем было занято 19,3 млн га [8].

Несмотря на ряд негативных явлений в сельском хозяйстве России, в хозяйствах страны все шире используют машинные технологии про-

Основные факторы и условия

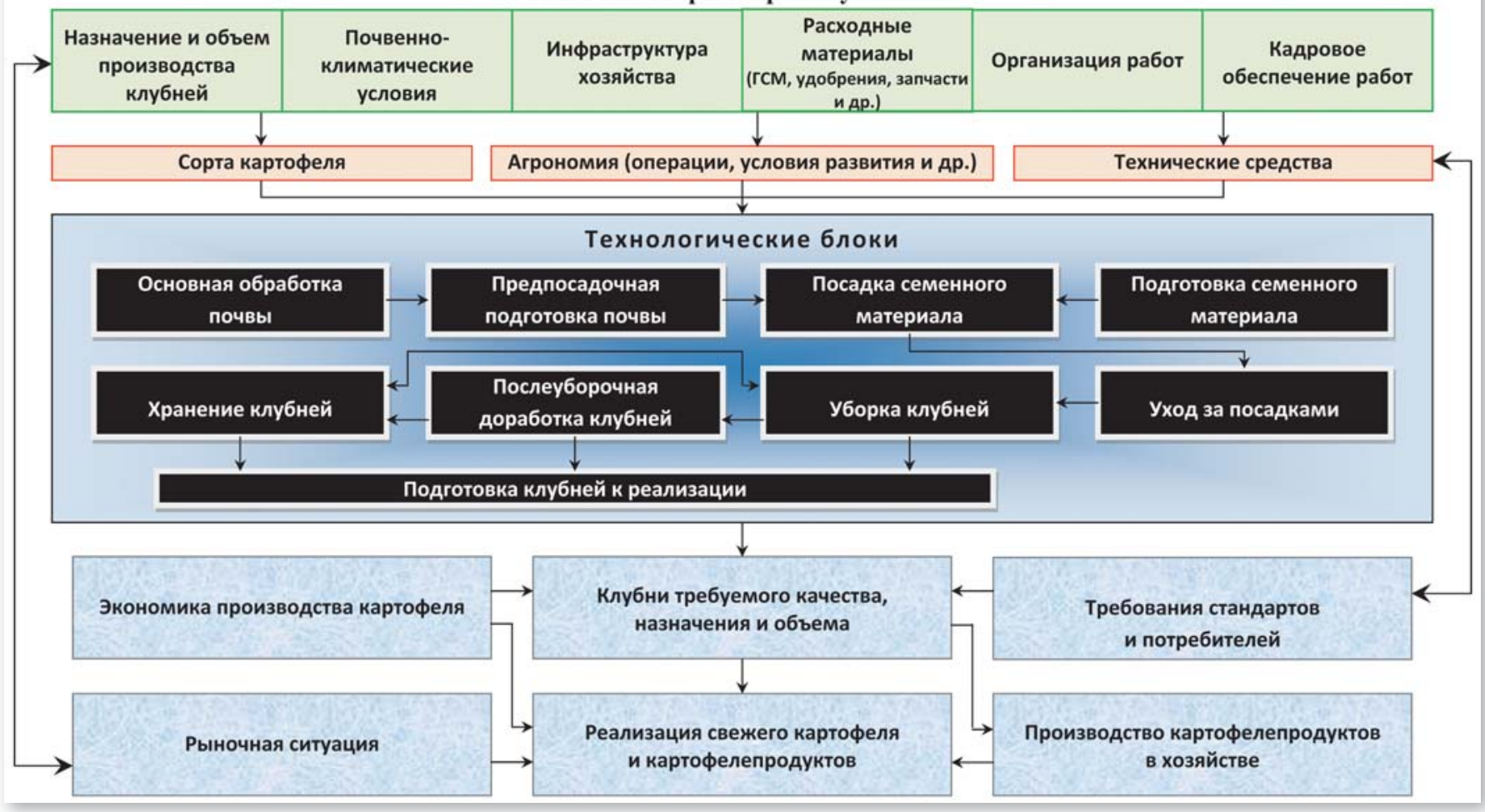

Общая технология производства, хранения и реализации картофеля 


\section{Производство картофеля в регионах мира, тыс. т (1990-2013 годы)}

\begin{tabular}{|l|c|c|c|c|}
\hline \multirow{2}{*}{ Регионы мира } & \multicolumn{5}{|c|}{ Год } \\
\cline { 1 - 5 } & 1990 & 2000 & 2010 & 2013 \\
\hline Африка & 8222 & 13214 & 25527 & 30499 \\
\hline Азия & 64182 & 121429 & 159074 & 187219 \\
\hline Европа & 160268 & 149121 & 197684 & 113295 \\
\hline Северная Америка & 21244 & 27863 & 22760 & 24465 \\
\hline Южная Америка & 11368 & 14270 & 16766 & 18139 \\
\hline Океания & 1442 & 1702 & 1806 & 1837 \\
\hline Мир в целом & 266825 & 327599 & 333917 & 376453 \\
\hline
\end{tabular}

изводства картофеля. При большом разнообразии почвенно-климатических условий в регионах страны растет количество крупных производителей картофеля. В настоящее время, по данным Минсельхоза РФ, в таких хозяйствах производится $18 \%$ клубней от общего годового объема. Реальный пример развития подобных хозяйств - ЗАО «Озеры» Московской области и ряд других.

Развитие отечественного картофелеводства на основе использования машинных технологий соответствует мировым тенденциям, но идет крайне медленными темпами. Основная причина состоит в существенном сокращении отечественной базы его семеноводства и в практическом прекращении широко проводимых ранее организациями разных ведомств, включая Минсельхоз РФ, комплексных поисковых, научно- исследовательских и опытно-конструкторских работ по созданию современных технологий и техники для широкого диапазона наших условий и их базовых компонентов. Нуждается в серьезном развитии инфраструктура хозяйств - производителей картофеля, включающая материально- техническую базу хранения, а в перспективе, и переработки картофеля.

Структурам власти следует осознать важность стимулирования активной совместной деятельности создателей, производителей и потребителей отечественной с. - х. техники. Только развитое собственное с.х. машиностроение и применение его продукции по современным технологиям на местах позволит России проводить самостоятельную и независимую политику по обеспечению продовольственной безопасности страны.

Необходима сбалансированная государственная поддержка активной, в том числе совместной, деятельности промышленности и сельского хозяйства в различных формах, широко применяемых сегодня в мировой практике, от развития научноисследовательской базы, подготовки высококвалифицированных специалистов, поддержки перспективных комплексных проектов и их широкого внедрения, содействия бизнесу и др., до организации инфраструктуры рынка и продвижения продукции развивающейся отрасли на этот рынок.

Развитие имеющихся производственных мощностей для выпуска современной с. - х. техники государство стимулирует в недостаточной степени. Наглядной иллюстрацией такого состояния может служить действующий более 20 лет завод ООО «Колнаг» (г. Коломна, Московская обл.) с современным производством и хорошими заготовительным, сварочным и механическим участками.

Должны быть созданы условия для привлечения существующих и образования новых малых и средних компаний и активной их деятельности по производству широкой номенклатуры комплектующих изделий (агрегатов, приводов и др.), что снизит и в перспективе исключит их импорт. Необходимо создать в стране развитое производство их широкой качественной номенклатуры. Подобный подход к организации производства современных машин позволит эффективнее использовать региональное машиностроение, что имеет важное значение для нашей страны с ее большой территорией.

При устойчивой мировой тенденции перехода к производству основного объема картофеля и овощей по машинным технологиям в крупных хозяйствах сохраняется значительное количество хозяйств малых форм - производителей этих культур во многих, в том числе развитых странах мира, например, в США, а также в России [7]. Необходимо учитывать потребность и особенности ее применения в малых формах хозяйствования, производящих зна- чительные объемы качественной с.х. продукции

Широкий ассортимент подобной техники производят фирмы EURO Jabelmann (Германия), F.LLISPEDO и IMAC (Италия), Krukowiak (Польша), японские фирмы Sanei Industry Со и Toyo Agricultural Machinery Manufacturing Со и др. [8, 19]. Она представляет интерес для отечественных производителей картофеля и овощей.

Развитию отечественного производства современной и надежной с.х. техники для хозяйств разных форм и ее эффективному использованию на местах по современным технологиям следует придать статус приоритетной государственной задачи и неуклонно обеспечивать и контролировать ее выполнение.

Опыт проведения комплексных работ в рамках государственных и других программ по созданию перспективных технологий и техники для сельского хозяйства показывает необходимость выполнения ряда важных условий и требований:

- основой подобных работ должно быть принятое на государственном уровне решение, определяющее заказчика, цели объемы работ и способы их финансирования, сроки выполнения и способы реализации полученных результатов;

- до начала работ должны быть определены и согласованы все исполнители с утверждением выполняемых ими частей работы и из их числа - ее головной исполнитель с соответствующими правами и обязанностями, включая решение текущих вопросов финансирования. В числе исполнителей должна быть организация, практически реализующая результаты работ, в т.ч. промежуточные, полученные в процессе их выполнения;

- предусматривается корректировка утвержденного плана работ по полученным положительным промежуточным их результатам с участием всех исполнителей и заказчика;

- оценка эффективности выполненных работ должна проходить не по косвенным оценкам и различным коэффициентам, а по реальным показателям их результатов (эффективность работы машин, объемы производства продукции и наработки в хозяйствах, показатели качества работы машин и др.);

- определяются перспективы расширения применения полученных результатов работ.

№11/2019 Картофель и овощи 
Номенклатура и объем импорта c. - х. техники должны быть обоснованными и учитывать наши условия и особенности и дополнять ее отечественное производство. При этом следует применять повышенные таможенные пошлины на ввоз готовых машин и оборудования.

Следует возобновить деятельность совместных научно-технических советов в ведущих организациях сельского хозяйства и промышленности, привлекая к работе в них специалистов из смежных ведомств. В свое время на таких советах систематически обсуждались результаты выполнения заданий, направления работ, итоги испытаний техники и др., вырабатывались и согласовывались рекомендации и предложения по совместным разработкам и решениям возникающих проблем и др. Необходимо активное развитие практически заброшенных МИС Минсельхоза РФ, играющих важную роль в создании и внедрении в российское многозональное сельское хозяйство новых машинных технологий и техники.

Как бы совершенна ни была техника для сельского хозяйства, она может эффективно работать только в определенных условиях. Необходим дифференцированный подход к размещению с.х. культур в наиболее благоприятных для этого зонах страны на основе специализации хозяйств и получать с мест готовые продукты в натуральном и переработанном виде. Специалистов для работ с современной техникой в хозяйствах следует готовить в институтах Минсельхоза РФ с использованием новейших ее образцов, создавать на местах условия для их активной и продуктивной деятельности.

Массовое производство и эффективное применение широкой номенклатуры современной и надежной отечественной с.- х. техники по современным технологиям в комплексе с развитием инфраструктуры хозяйств сократит потери урожая с. - х. продукции, повысит ее качество, позволит развить экспорт продовольственного сырья и продуктов и снизить вывоз из страны углеводородного сырья, которое не бесконечно. Выполнение названных мер создаст новые рабочие места и обеспечит рост общего благосостояния населения регионов и необходимый уровень продовольственной безопасности страны.
Библиографический список

1.Туболев С.С. и др. Машинные технологии и техника для производства картофеля. М.: Агроспас, 2010. 316 с.

2.Колчин Н.Н. и др. Технология и комплексы машин для возделывания важнейших сельскохозяйственных культур. Ч. І. Картофель. М.: ИНФРА-М, 1997. 104 с.

3.Ксеневич И.П. и др. Машиностроение. Энциклопедия. Сельскохозяйственные машины и оборудование T. IV-16. М.: Машиностроение, 1998. 720 с.

4.Кашин В.И. Не имитировать, а возрождать // Сельская жизнь. 2016. № 28. С. 4 .

5.Путин В.В. Послание Президента РФ Федеральному собранию от 1 декабря 2016 г. [Электронный ресурс] URL: https://base.garant.ru/71552000. Дата обращения: 18.01.19.

6.Колчин Н.Н. Возрождение отечественного сельхозмашиностроения - неотложная и важная государственная задача // Тракторы и сельхозмашины. 2016. № 10. C. 3-7.

7.Лищенко В.Ф. и др. Состояние и перспективы развития продовольственной системы России (на примере картофельного комплекса). М.: Экономика, 2016. 446 с.

8.Колчин Н.Н. и др. Специальная техника для производства картофеля в хозяйствах малых форм // Тракторы и сельхозмашины. 2012. № 5. С. 48-53.

9.Туболев С.С., Колчин Н.Н. Развитие отечественного сельскохозяйственного машиностроения на примере производства специальной техники для картофелеводства и овощеводства. М.: ФГБНУ «Росинформагротех», 2011. С. 68

\section{Об авторах}

\section{Колчин Николай Николаевич}

доктор техн. наук, профессор,

гл.н.с., Федеральное государственное бюджетное научное учреждение «Федеральный научный агроинженерныЙ центр ВИМ» (ФГБНУ ФНАЦ ВИМ) Леунов Владимир Иванович, доктор с. - х. наук, профессор, и. о. декана факультета агрономии и биотехнологии, ФГБОУ ВО РГАУ - МСХА имени К.А. Тимирязева.

E-mail:vileunov@mail.ru

Potato fields of Russia are waiting for quality seeds, new technologies and equipment

N.N. Kolchin, DSc, prof., chief research fellow, Federal State Budgetary

Scientific Institution «Federal Scientific Agroengineering Center VIM» (FSBSI FSAC VIM)

V.I. Leunov, DSc, prof, acting dean of faculty of agronomy and biotechnology, Russian State Agrarian University - Moscow Timiryazev Agricultural Academy

\section{E-mail: vileunov@mail.ru}

Summary. The article highlights the world experience of agricultural engineering and highlights the main reasons for the backlog of this industry in Russia. A number of proposals for the development and implementation of complex works on the creation and introduction of advanced technologies and equipment in agriculture in Russia. The main tasks for the creation and production of agricultural machinery in modern conditions are formulated.

Keywords: potato growing, machinery, technologies.

\section{Николай Николаевич Колчин}

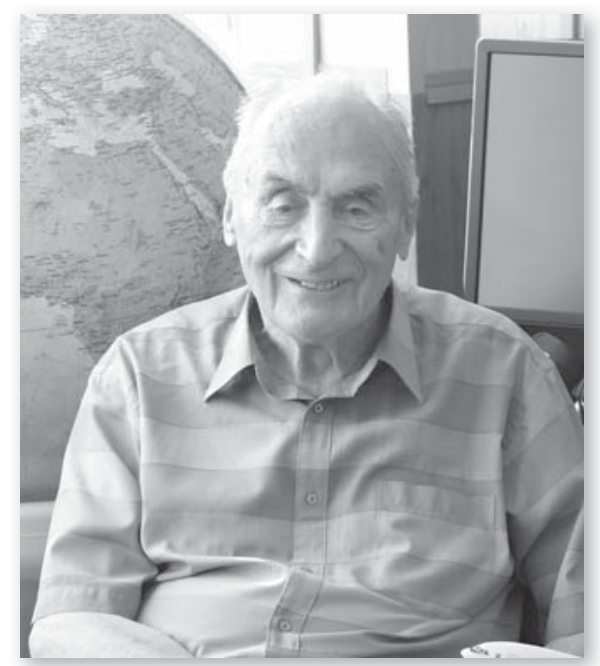

На 94 году ушنел изз жизЗнй выдающийся ученый, заслуженный деятель науки и техники Российской Федерации, доктор техн. наук, профессор, академик Российской академии транспорта Николай Николаевич Колчин.

Закончив в 1949 году с отличием Московский авиационный институт, он был направлен на работу во Всесоюзный НИИ с.-х. машиностроения (ВИСХОМ), где проработал до 2006 года. До последнего времени Николай Николаевич продолжал свою научную деятельность в Федеральном агроинженерном центре ВИМ.

Вся его жизнь была посвящена развитию вопросов механизации в сельском хозяйстве и, в частности, в картофелеводстве. Он - автор более 200 научных публикаций, 145 авторских свидетельств и патентов. Разработки Н.Н. Колчина внедрены в разных странах.

Большое внимание он уделял подготовке научных кадров. В разные годы был членом диссертационных советов по специальности 05.20.01 при ВИСХОМ, ВИМ, РГАТУ, ВСТИСП. Непосредственно под его руководством было подготовлено 17 кандидатов и 6 докторов наук. Он был вдумчивым, эрудированным, доброжелательным, трудолюбивым человеком, настоящим примером для молодежи.

Ученые в области с.-х. машиностроения, сотрудники ВИМ, ВНИИКХ имени А.Г. Лорха, РГАТУ имени П.А. Костычева, МСХА имени К.А. Тимирязева, редакция журнала «Картофель и овощи», многочисленные ученики и коллеги выражают искренние соболезнования родным и близким Николая Николаевича. 